\title{
Elaboração E APLICAÇÃo de UMa SituaÇÃo de Estudo A PARTIR DO CONTEÚdo RADIOATIVIDADE: EM FOCO A FORMAÇÃO INICIAL EM QUÍMICAS
}

\author{
ELABORATION AND APPLICATION OF A STUDY SITUATION FROM THE \\ RADIOACTIVITY CONTENT: FOCUS ON INITIAL CHEMISTRY TRAINING
}

DOI: $\underline{\text { 10.23926/RPD.2526-2149.2020.v5.n3.p1747-1765.id838 }}$

\section{Gean Aparecido Zapateiro}

Mestre em Ensino de Ciências Humanas, Sociais e da Natureza (UTFPR)

Professor na Secretaria de Estado da Educação do Paraná (SEED)

geanzapateiro@utfpr.edu.br

\section{Márcia Camilo \\ Figueiredo}

Doutora em Educação para a Ciência (UNESP)

Docente na Universidade Tecnológica Federal do Paraná, Câmpus Londrina (UTFPR) marciafigueired@utfpr.edu.b $\underline{r}$
Resumo: O objetivo da pesquisa foi analisar as contribuições da elaboração e aplicação de uma Situação de Estudo (SE) com o conteúdo de Radioatividade na formação inicial de licenciandos em química. A SE foi planejada e fundamentada pela proposta didáticopedagógica dos Três Momentos Pedagógicos. Participaram da pesquisa treze acadêmicos de um curso de Licenciatura em Química na aplicação de uma SE e, no final, responderam a um questionário dissertativo. O método de estruturação dos dados foi realizado conforme a análise de conteúdo de Bardin. Os resultados evidenciaram que a SE colaborou para a formação docente dos licenciandos, proporcionando-lhes novos saberes em como elaborar aulas a partir do contexto histórico-social, e aprenderam que este estudo possibilita aos alunos a compreensão de uma ciência que não está pronta e acabada, e, sim, em constante desenvolvimento, permeada por fatores sociais, econômicos, políticos.

Palavras-chave: Formação de Professores. Momentos Pedagógicos. Ensino de Química.

\begin{abstract}
The objective of the research was to analyze the contributions of the elaboration and application of a Study Situation (SE) with the content of Radioactivity in the initial training of undergraduate chemistry students. The ES was planned and based on the didactic-pedagogical proposal of the Three Pedagogical Moments. Thirteen academics from a Chemistry Degree course in the application of an SE participated in the research, and at the end they answered a dissertation questionnaire. The method of structuring the data was carried out according to Bardin's content analysis. The results showed that SE collaborated for the teacher training of undergraduate students, providing them with new knowledge on how to prepare classes from the historical-social context, and learned that this study allows students to understand a science that is not ready and finished. But in constant development, permeated by social, economic, political factors.
\end{abstract}

Keywords: Teacher Education. Pedagogical Moments. Chemistry Teaching. 


\section{INTRODUÇÃO}

O paradigma de ensino tradicional continua em evidência nas práticas pedagógicas de muitos professores, principalmente daqueles que ainda acreditam que deter e dominar conteúdos organizados e estruturados em cada disciplina garantem aos sujeitos a construção de competências e habilidades para atuar no mundo cada vez mais globalizado (SANTOS; MALDANER, 2010; ZANON; MALDANER, 2010).

O processo de ensino pautado no método tradicional também não condiz com as finalidades preconizadas nas Leis, como na Lei de Diretrizes e Bases da Educação, sobretudo, quando o professor, ao transmitir os conteúdos, não permite ao estudante falar, se comunicar entre os seus pares, ou rever suas concepções.

Esta maneira de conceber o ensino não se enquadra com o que propõem os Parâmetros Curriculares Nacionais para o Ensino Médio, porque além de não permitir aos estudantes construírem uma visão de mundo mais articulada e menos fragmentada dos conteúdos, também os excluem de um mundo no qual estão inseridos e que está em constantes transformações (BRASIL, 2000).

Mizukami (1986) e Saviani (1991), por exemplo, explicam que as principais características do método tradicional de ensino se concentram em realizar correções de exercícios relacionadas aos conteúdos abordados, e que neste processo o professor é o ator principal e o aluno se torna o agente passivo e receptivo.

Muitas são as demandas exigidas para a educação escolar, como oportunizar situações para os estudantes compreenderem os conhecimentos abordados nas Ciências da Natureza e suas Tecnologias, a partir dos seus contextos históricos (BRASIL, 2006; 2017). Para isso, é necessária também uma ruptura de prática pedagógica de professores formados pelo modelo de Racionalidade Técnica, uma prática não fundamentada em princípios metodológicos, onde o sujeito a executa sem a reflexão rompendo o elo entre a teoria e a prática para formação profissional (SAVIANI, 2009). Este tipo de modelo limita o professor em possuir somente o domínio do conhecimento específico para então ser aplicado no ensino, não possibilitando o saber pedagógico (GALIAZZI, 2014).

Dessa maneira, afirma-se que este tipo de formação é falho, uma vez que o docente não consegue fazer uma ponte entre os dois saberes (específico e pedagógico) (GALIAZZI, 2014). Este modelo pode ser superado por meio da participação dos licenciandos em pesquisas e em grupos de reflexão com formadores, licenciandos, mestrandos e doutorandos, possibilitando a articulação entre ensino e pesquisa. Assim como em outros trabalhos, tem-se mostrado 
relevante a integração da pesquisa com a formação inicial de licenciandos (TEIXEIRA, 2003; DIAS; CARDOSO; DEBASTIANI, 2015; DATTEIN; GULLICH; ZANON, 2018; SOUZA; CHAPANI, 2019).

Neste viés, entendemos que, para ocorrer uma ruptura, é preciso que cursos de graduações em modalidade de Licenciatura ofertem a seus acadêmicos atividades didáticopedagógicas que os tornem aptos a pensar, refletir e analisar quais objetivos o ensino tradicional oferece ao aluno.

Conforme os Parâmetros Curriculares Nacionais (PCNs) e a Base Nacional Comum Curricular (BNCC), os futuros professores de química devem proporcionar aos alunos saberes que os permitam construir uma visão de mundo mais articulada, menos fragmentada, na qual o aluno se descubra como participante de um mundo em constante transformação. Portanto, tornam-se urgentes novas práticas educativas ainda na sua formação inicial e novas estratégias de ensino que possam ser ensinadas em cursos, minicursos, palestras, projetos de pesquisa, programas de iniciação à docência, grupos de estudos, entre outros (BRASIL, 2000; 2017).

Nas diretrizes do Ministério da Educação sobre Formação de Professores para a Educação Básica, verifica-se a responsabilidade atribuída à universidade no que diz respeito à formação docente para o exercício de um trabalho significativo para a sociedade e, em particular, para a comunidade escolar (BRASIL, 2015).

Em virtude dos fatos mencionados, uma Situação de Estudo (SE) foi planejada a partir da proposta curricular inovadora fundada pelo Grupo Interdepartamental de Pesquisa sobre Educação em Ciências, da Universidade Regional do Noroeste do Estado do Rio Grande do Sul (GIPEC-UNIJUÍ), no ano de 2000, a qual consiste em utilizar a SE para organizar o conhecimento e fragmentar a abordagem linear dos conteúdos.

Para isso, selecionou-se o conteúdo básico de radioatividade a partir do aporte teórico da História da Química, porque acredita-se que nesta abordagem o sujeito entende diversos processos que estão presentes no seu dia a dia, como diagnosticar e tratar doenças na medicina nuclear, produzir energia elétrica, e impedir o crescimento de agentes produtores e de deterioração nos alimentos, por exemplo.

Além disso, a escolha do ensino abordado por meio da História da Química também contribui para entender que o(s) conhecimento(s) científico(s) ensinados nas escolas "[...] não é algo pronto, acabado e inquestionável, mas em constante transformação" (PARANÁ, 2008, p. 51). Ou seja, fazem parte de um processo de elaboração e transformação dos saberes que ocorrem “[...] em função das necessidades humanas, uma vez que a ciência é construída por 
homens e mulheres, portanto, falível e inseparável dos processos sociais, políticos e econômicos" (PARANÁ, 2008, p. 51).

Neste contexto, buscou-se responder o problema elaborado na forma de pergunta: “Quais impactos ocorrem na formação inicial de professores de química quando se aplica uma Situação de Estudo do conteúdo de radioatividade a partir de seu contexto histórico-social?”. Para isso, o objetivo foi analisar as contribuições da elaboração e aplicação de uma Situação de Estudo (SE) com o conteúdo de Radioatividade na formação inicial de licenciandos em química.

\section{REFERENCIAL TEÓRICO}

\subsection{HistóRIA DA QUíMICA NO ENSINO}

Desde a década de 90, há na literatura autores que reportam a respeito do fracasso no ensino de Ciências. Por exemplo, Matthews (1994) citou que, nas últimas décadas, muitos trabalhos de pesquisa em ensino de Ciências têm detectado o analfabetismo científico tanto de professores como de alunos, refletindo assim nas aulas de Ciências.

Neves (1988, p. 74) também descreveu: “O que temos visto nas últimas décadas é a ciência sendo apreendida como um dado e não como uma possibilidade de construção e integração com as demais ciências e com as necessidades diárias do cidadão comum”.

Dito isso, profissionais da educação e pesquisadores têm se empenhado em reverter tal situação, principalmente quando reconhecem que a Ciência faz parte do "patrimônio cultural da humanidade". E nas orientações da Base Nacional Comum Curricular (BNCC) para a Educação Básica, há um conjunto orgânico e progressivo que o professor precisa trabalhar a fim de garantir o desenvolvimento de cada aluno, de modo a prepará-lo para exercer a sua cidadania e estar qualificado para o trabalho (BRASIL, 2017).

Neste contexto, na atual BNCC, no Art. $4^{\circ}$, verifica-se, entre as competências gerais e objetivos de aprendizagem, que o aluno precisa: "1. Valorizar e utilizar os conhecimentos historicamente construídos sobre o mundo físico, social, cultural e digital para entender e explicar a realidade, continuar aprendendo e colaborar para a construção de uma sociedade justa, democrática e inclusiva; [...] (BRASIL, 2017, p. 4, grifo nosso). Para isso, o professor precisa estar formado e apto a trabalhar os conteúdos a partir do seu contexto histórico para que atenda as atuais recomendações da BNCC.

O trabalho com a abordagem histórica permite que o aluno entenda a ciência como uma construção de conhecimentos e discuta os aspectos da natureza da ciência, além disso, também propicia ao aluno o entendimento de que "a ciência não é uma coisa isolada de todas as outras, 
mas sim faz parte de um desenvolvimento histórico, de uma cultura, de um mundo humano, sofrendo influências e influenciando por sua vez muitos aspectos da sociedade" (MARTINS, 2006, p. 17, grifo nosso). Para esse entendimento, a ciência precisa ser:

[...] ensinada como um saber histórico e provisório, tentando fazer com que os alunos participem, de algum modo, no processo de elaboração do conhecimento científico, com suas dúvidas e incertezas, e isso também requer deles uma forma de abordar o aprendizado como um processo construtivo, de busca de significados e de interpretação, em vez de reduzir a aprendizagem a um processo repetitivo ou de reprodução de conhecimentos pré-cozidos, prontos para o consumo (DUCHSL, 1994 apud POZO; CRESPO, 2006, p. 21).

Para o cumprimento destes objetivos, a universidade precisa habilitar/formar docentes aptos a ensinar conteúdos científicos a partir do seu contexto histórico, para que assim, ao trabalhá-los, consigam ensinar aos alunos:

[...] que o processo de construção das teorias científicas não é o simples acúmulo de informações, mas uma construção de ideias que envolvem diferentes análises e negociações pela comunidade científica, em um constante processo de revisão dos conceitos científicos vigentes à época, portanto, marcando a ciência como uma atividade caracterizada pela refutabilidade e transitoriedade (CHAVES; SANTOS; CARNEIRO, p. 270).

A abordagem histórica de conteúdos propicia ao aluno refletir a respeito do que aconteceu e ocorre atualmente, compreendendo assim o desenvolvimento da ciência (MARTINS, 2006). Neste caso, o papel do professor é fundamental durante os processos de ensino e de aprendizagem para que o aluno entenda que os conhecimentos abordados no ensino de química são construções provisórias de um aperfeiçoamento que podem evoluir de acordo com o contexto histórico.

\subsection{SituAÇÃo de ESTUdo (SE) NA FORMAÇÃo INICIAL DE PROFESSORES DE QUíMICA}

O parecer CNE/CES n ${ }^{\circ} 1.303 / 2001$, que trata das Diretrizes Curriculares Nacionais para os Cursos de Química, reporta sobre as garantias da formação do profissional para exercer a docência, e ser capaz de atender às exigências em relação ao papel da Ciência e à sua natureza para sociedade, formando o sujeito para exercer de modo pleno a sua cidadania (BRASIL, 2001).

Para isso, os Licenciandos em Química precisam receber uma formação “[...] sólida e abrangente em conteúdo dos diversos campos da Química, preparação adequada à aplicação pedagógica do conhecimento e experiências de Química e de áreas afins na atuação profissional como educador na educação fundamental e média” (BRASIL, 2001, p. 4). Somado a isso, constata-se que atividades de como utilizar estratégias e matérias de apoio e de apropriação de 
novas metodologias e abordagens, e atividades de incentivo ao trabalho em grupo, por exemplo, sejam trabalhadas no componente curricular de cursos de formação docente (BRASIL, 2001).

No que diz respeito à formação de professores para o Ensino de Química, na literatura científica, é evidenciada, nos resultados de pesquisas, como as de Shön (1995), Maldaner (2006) e Carvalho, Gil-Perez, (2011), a intenção de buscar melhorias para Educação Básica, visando à construção de novos conhecimentos pedagógicos para melhoria da qualidade do processo de ensino e de aprendizagem. Para isso, o professor carece de uma formação adequada, ou seja, de obter diversos saberes que permita que ele atue na área de ensino.

Para tanto, cada vez mais a formação do professor apto a trabalhar no atual contexto escolar tem exigido tanto do acadêmico como dos que formam esse profissional participações em várias atividades que os aperfeiçoem a obter saberes conceituais, teóricos e metodológicos (cursos, palestras, congressos, orientações, projetos, publicações e apresentações de pesquisas, entre outros).

A abordagem de novas práticas educativas e estratégias de ensino ainda na formação inicial docente é um ponto primordial, pois colabora com a futura profissão e melhora a qualidade da educação (CARVALHO; GIL- PÉREZ, 2011). Para isso, os autores ressaltam que, para ministrar aulas, é preciso ter domínio de competências específicas, em particular a pedagógica, a qual precisa ser aprendida e desenvolvida.

A partir do ano de 2001, os professores da área de Ciências da Natureza e suas Tecnologias, junto ao Grupo Interdepartamental de Pesquisa sobre Educação em Ciências, da Universidade Regional do Noroeste do Estado do Rio Grande do Sul (GIPEC-UNIJUÍ), iniciaram a implementação curricular para a formação de professores, possibilitando a ideia de uma nova organização de ensino por meio da Situação de Estudo (SE) (KINALSKI et al, 2007).

A SE é uma proposta inovadora curricular, que prioriza uma abordagem contextualizada e interdisciplinar dos conteúdos de Ciências, visando superar o ensino tradicional. Na SE, as abordagens de conteúdos científicos fornecem subsídios para o aluno compreender o motivo do aprendizado, e os professores têm autonomia nas escolhas de conteúdo a ser trabalhados, podendo repensar e selecionar os mais apropriados para a realidade dos estudantes (KINALSKI et al, 2007). Ou seja, "[...] a SE é reorganizada conforme transcorrem as aulas, mudando de acordo com a turma em que se está trabalhando, não deixando de considerar os conceitos básicos" (KINALSKI et al, 2007, p. 363).

Neste sentido, entende-se que, na aplicação de uma SE, pode-se superar o método de tradicional de ensino, pois é uma proposta "rica conceitualmente, visa a romper com a 
apresentação linear dos conteúdos, desenvolvendo compressões intercomplementares e transdisciplinares" (KINALSKI et al, 2007, p. 358). Além disso, a SE pode possibilitar a articulação de saberes e do conteúdo de Ciências, e favorecer a formação de cidadãos críticos que sejam capazes de analisar o contexto social no qual estão inseridos.

Maldaner e Zanon (2004) ressaltam que a SE é uma proposta que precisa estar inserida de acordo com o contexto do aluno para que ele possa compreender a importância da química na vida e dar significados aos acontecimentos relacionados à ciência no seu cotidiano. Para os autores, a SE pode: “[...] contemplar essa complexidade que é o trabalho pedagógico escolar. Pelo fato de partir da vivência social dos alunos, ela facilita a interação pedagógica necessária à construção da forma interdisciplinar de pensamento e à produção da aprendizagem significativa" (MALDANER; ZANON, 2004, p. 58).

De acordo com Frison et al. (2007, p. 340), em uma Situação de Estudo, “é necessário fugir da estrutura linear em que são trabalhados todos os conteúdos numa sequência de prérequisitos". Outra questão fundamental descrita pelos autores é que "a SE não exige prérequisitos, o que muda é o grau de complexidade dos conceitos científicos, pois estes são abordados por serem necessários para compreender a situação em estudo" (FRISON et al, 2007, p. 340). Diante do evidenciado, a Situação de Estudo é pertinente a esta pesquisa para que seja abordado o conteúdo de radioatividade a partir do contexto histórico-social na formação inicial do professor de química.

\section{Metodologia}

A metodologia utilizada na pesquisa foi a do tipo qualitativa, por oferecer ao pesquisador características durante a investigação, como ter atenção e preocupação com a obtenção de dados em todo o seu processo, o qual ocorre no ambiente natural junto aos participantes, oportunizando também ao pesquisador fazer a análise neste contexto, respeitando o modo de registro e de transcrição (BOGDAN; BIKLEN, 1994).

Participaram da pesquisa 13 (treze) acadêmicos de um curso de Licenciatura em Química, bolsistas do PIBID - Programa Institucional de Bolsa de Iniciação à Docência, em uma Universidade Tecnológica pública, no Estado do Paraná. Portanto, uma pesquisa de natureza prática, descritiva e classificada como de campo, onde a coleta de dados se realiza junto às pessoas (BOGDAN; BIKLEN, 1994).

Todos os sujeitos foram mantidos no anonimato e identificados por códigos. Por exemplo, a letra L se refere aos licenciandos. A letra M é referente ao gênero Masculino, e a F, 
ao gênero Feminino dos licenciandos; os números 1 a 13 indicam a quantidade de participantes. Por exemplo, LM1 trata do licenciando do gênero masculino 1. Desta forma, os códigos dos participantes são: LM1, LF2, LF3, LF4, LF5, LF6, LF7, LF8, LM9, LF10, LM11, LM12 e LF13.

\title{
3.1. Coletas de dados: o deSEnvolvimento da Situação de Estudo (SE)
}

O planejamento da SE foi fundamentado pela proposta dos Três Momentos Pedagógicos (3MP) de Delizoicov, Angotti e Pernambuco (2007), estruturada e conhecida da seguinte maneira: "Problematização Inicial: apresentam-se questões ou situações reais que os alunos conhecem e presenciam e que estão envolvidas nos temas. Nesse momento pedagógico, os alunos são desafiados a expor o que pensam sobre as situações [...]”. (MUENCHEN; DELIZOICOV, 2014, p. 620, grifo dos autores). Depois, tem-se a “Organização do

Conhecimento: momento em que, sob a orientação do professor, os conhecimentos de física necessários para a compreensão dos temas e da problematização inicial são estudados" (MUENCHEN; DELIZOICOV, 2014, p. 620, grifo dos autores). E, por último, tem-se a:

\begin{abstract}
Aplicação do Conhecimento: momento que se destina a abordar sistematicamente o conhecimento incorporado pelo aluno, para analisar e interpretar tanto as situações iniciais que determinaram seu estudo quanto outras que, embora não estejam diretamente ligadas ao momento inicial, possam ser compreendidas pelo mesmo conhecimento (MUENCHEN; DELIZOICOV, 2014, p. 620).
\end{abstract}

A aplicação da SE foi realizada em 4 encontros, totalizando 15 horas. Segue, no quadro 1, um resumo de como foi planejada e desenvolvida a SE nos dois primeiros encontros com os licenciandos. Sendo o $1^{\circ}$ para apresentação da pesquisa, fundamentação teórica, leitura do documento de consentimento e assinatura do termo de participação na pesquisa.

Quadro 1 - Estruturação e aplicação da Situação de Estudo

\begin{tabular}{|c|c|c|c|}
\hline Encontros & Atividade & Descrição & Recursos utilizados \\
\hline $\mathbf{1}^{\mathbf{o}}$ & $\begin{array}{l}\text { Apresentação da } \\
\text { pesquisa. } \\
\text { Fundamentação } \\
\text { teórica }\end{array}$ & $\begin{array}{c}\text { Foi apresentada a importância da } \\
\text { abordagem histórica para o Ensino de } \\
\text { Ciências, a fim de evidenciar como a } \\
\text { História da Ciência pode ser empregada a } \\
\text { favor de uma aprendizagem significativa. } \\
\text { Fez-se a leitura do documento de } \\
\text { consentimento e assinatura do termo de } \\
\text { participação na pesquisa. }\end{array}$ & $\begin{array}{l}\text { PowerPoint. } \\
\text { Leitura e assinatura do } \\
\text { termo de participação } \\
\text { na pesquisa. }\end{array}$ \\
\hline $2^{\circ}$ & $\begin{array}{c}\mathbf{1}^{\mathbf{0}} \text { Problematização } \\
\text { Inicial (PI) } \\
\text { Vídeo "Tudo se } \\
\text { Transforma: Marie } \\
\text { Curie" }\end{array}$ & $\begin{array}{c}\text { Verificação de conhecimentos prévios dos } \\
\text { licenciandos por meio de questionamentos } \\
\text { a fim de fomentar discussões e } \\
\text { levantamento de dúvidas a respeito do } \\
\text { conteúdo. }\end{array}$ & PowerPoint e Youtube \\
\hline
\end{tabular}




\begin{tabular}{|c|c|c|c|}
\hline & & $\begin{array}{c}\text { O objetivo foi despertar a curiosidade dos } \\
\text { licenciandos sobre a descoberta feita por } \\
\text { Marie, propiciou-se aos licenciandos a } \\
\text { compreensão de conhecimentos da } \\
\text { descoberta a partir dos seus contextos } \\
\text { históricos. }\end{array}$ & \\
\hline & \multirow{2}{*}{$\begin{array}{l}2^{\circ} \text { Organização do } \\
\text { Conhecimento } \\
\text { (OC) } \\
\text { Aula teórica: } \\
\text { História da } \\
\text { radioatividade }\end{array}$} & $\begin{array}{l}\text { A partir deste momento, almejou-se ensinar } \\
\text { aos licenciandos os conhecimentos de } \\
\text { radioatividade necessários para a } \\
\text { compreensão do tema e da Problematização } \\
\text { Inicial. }\end{array}$ & \\
\hline & & $\begin{array}{c}\text { Apresentou-se em Power Point aos } \\
\text { licenciandos sobre a evolução do } \\
\text { conhecimento da radioatividade, desde as } \\
\text { contribuições de Crookes, Röntgen, } \\
\text { Becquerel e do casal Pierre e Marie Curie, } \\
\text { tendo como enfoque a descoberta dos } \\
\text { elementos Radio e Polônio, estudos do } \\
\text { casal Curie. }\end{array}$ & \\
\hline $3^{\circ}$ & $\begin{array}{c}\text { Aplicação do } \\
\text { Conhecimento (AC) } \\
\text { Aula teórica } \\
\text { contextualizada: } \\
\text { conceitos da } \\
\text { radioatividade tipos } \\
\text { de emissões, cinética } \\
\text { das desintegrações } \\
\text { radiativas, fissão e } \\
\text { fusão nuclear. }\end{array}$ & $\begin{array}{l}\text { Trabalhou-se cada conceito de } \\
\text { radioatividade por meio da abordagem } \\
\text { histórica, permitindo a construção do } \\
\text { conhecimento. }\end{array}$ & $\begin{array}{l}\text { PowerPoint e Quadro- } \\
\text { Negro }\end{array}$ \\
\hline \multirow{4}{*}{$4^{o}$} & $\begin{array}{c}\text { AC } \\
\text { Vídeo "Tudo se } \\
\text { transforma: Energia } \\
\text { e Impacto } \\
\text { Ambiental, Energia } \\
\text { Nuclear parte 1 e 2". }\end{array}$ & $\begin{array}{l}\text { Exibiu-se o vídeo que aborda os mitos e } \\
\text { verdades sobre radioatividade; trabalhou-se } \\
\text { os conteúdos abordados anteriormente. O } \\
\text { objetivo foi o de relacionar o conteúdo com } \\
\text { as aplicações que foram trabalhadas na } \\
\text { próxima atividade. }\end{array}$ & \multirow{4}{*}{$\begin{array}{l}\text { PowerPoint. } \\
\text { Youtube. } \\
\text { Jogo Didático: } \\
\text { Twister Químico- } \\
\text { Radioatividade }\end{array}$} \\
\hline & $\begin{array}{c}\mathbf{A C} \\
\text { Aplicações das } \\
\text { Reações Nucleares }\end{array}$ & $\begin{array}{c}\text { Apresentou-se em Power Point os } \\
\text { benefícios da radioatividade para a } \\
\text { humanidade e as aplicações que temos até } \\
\text { hoje. }\end{array}$ & \\
\hline & $\begin{array}{c}\text { AC } \\
\text { Perigo e Acidentes } \\
\text { nucleares }\end{array}$ & $\begin{array}{c}\text { Apresentou-se em Power Point para os } \\
\text { licenciandos quais os malefícios e perigos } \\
\text { fisiológicos que a radioatividade pode } \\
\text { provocar no ser humano. } \\
\text { Em seguida, exibiu-se o vídeo: “Arquivo N } \\
\text { - Acidentes Nucleares”, que mostra os } \\
\text { acidentes nucleares que marcaram a } \\
\text { história. }\end{array}$ & \\
\hline & $\begin{array}{c}\text { AC } \\
\text { Aplicação de um } \\
\text { jogo didático } \\
\text { denominado Twister } \\
\text { Químico - } \\
\text { Radioatividade. } \\
\text { Aplicação de } \\
\text { questionário final } \\
\text { para a avaliação da } \\
\text { SE } \\
\end{array}$ & $\begin{array}{l}\text { Utilizou-se o jogo didático para } \\
\text { interpretação de situações propostas na } \\
\text { Problematização Inicial com o } \\
\text { conhecimento adquirido no segundo } \\
\text { momento. A aplicação do jogo teve como } \\
\text { objetivo uma aprendizagem significativa } \\
\text { por meio de metodologias diferenciadas } \\
\text { para proporcionar aos licenciandos uma } \\
\text { melhor compreensão dos conteúdos. }\end{array}$ & \\
\hline
\end{tabular}

Fonte: Dados da pesquisa 
No Quadro 1, a Problematização Inicial (PI) ocorreu no segundo encontro, no qual os pesquisadores questionaram os licenciandos de tal maneira que falaram as suas ideias a respeito do assunto, fomentaram discussões, levantaram dúvidas e indagações, as quais foram refletidas e dialogadas. As questões propostas na PI seguem no Quadro 2.

Quadro 2 - Perguntas propostas na Problematização Inicial (PI)

\begin{tabular}{|c|}
\hline $\begin{array}{l}\text { 1. Quando vocês ouvem/escutam a palavra radioatividade, o que pensam sobre esse } \\
\text { assunto? }\end{array}$ \\
\hline $\begin{array}{l}\text { 2. Alguém poderia citar o nome de algum (a) cientista que colaborou com a construção do } \\
\text { conteúdo de radioatividade? }\end{array}$ \\
\hline $\begin{array}{l}\text { 3. Quais os benefícios da radioatividade para a vida pessoal das pessoas? E para a } \\
\text { sociedade? E para o meio ambiente? }\end{array}$ \\
\hline $\begin{array}{l}\text { 4. Quais os malefícios da radioatividade para a vida pessoal das pessoas? E para a } \\
\text { sociedade? E para o meio ambiente? }\end{array}$ \\
\hline $\begin{array}{l}\text { 5. Alguém pode dar um exemplo da aplicação da radioatividade no tratamento de doenças } \\
\text { ou em procedimentos diagnósticos? }\end{array}$ \\
\hline 6. Sabem qual procedimento de diagnóstico de fraturas? \\
\hline $\begin{array}{l}\text { 7. Vocês devem conhecer algum amigo ou familiar que utiliza aparelho dentário, antes de } \\
\text { colocá-lo, deve-se fazer uma documentação ortodôntica? Conhecem o procedimento da } \\
\text { documentação? Durante o procedimento, deve-se usar uma roupa especifica? Por quê? }\end{array}$ \\
\hline
\end{tabular}

Fonte: Dados da pesquisa

Ainda no segundo encontro (Quadro 1), na Organização do Conhecimento (OC), trabalhou-se todo o conteúdo necessário para solucionar os problemas levantados na PI, portanto, o conceito foi relacionado aos problemas. Para isso, iniciou-se, por meio de uma aula teórica contextualizada, a radioatividade, sempre com retomada das indagações feitas na PI. Os recursos utilizados foram vídeos, imagens e o quadro-negro. No quadro 3, estão organizados os conteúdos trabalhados na Situação de Estudo (SE).

Quadro 3 - Organização dos conteúdos trabalhados na SE

\begin{tabular}{|c|} 
Desenvolvimento dos conteúdos da Radioatividade: \\
$>$ História da Radioatividade \\
$>$ Fatos e curiosidades históricos \\
Emissões radioativas \\
- Alfa \\
• Beta \\
• Gama \\
$>$ Cinética das desintegrações radioativas \\
Fenômenos radiativos \\
Fissão nuclear \\
$\circ$ Produção de urânio; \\
$\circ$ Produção de urânio no Brasil e no mundo; \\
$\circ$ Combustível nuclear \\
$\circ$ Bomba atômica \\
$\circ$ Bombardeamento Hiroshima e Nagasaki \\
$\circ$ Reatores Nucleares
\end{tabular}




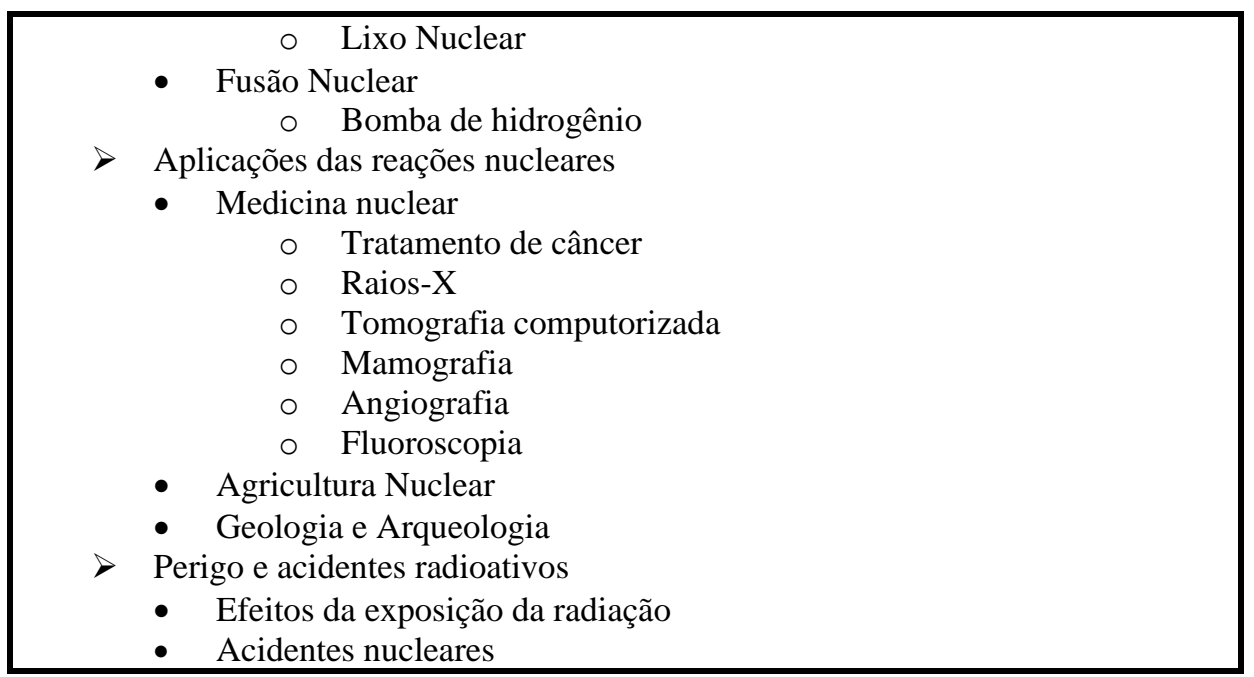

Fonte: Dados da pesquisa

Após abordar todo o conteúdo descrito no quadro 3, seguiram-se as informações contidas no quadro 1, as quais foram trabalhadas nos próximos encontros da SE (Quadro 1).

No terceiro encontro, a Aplicação do Conhecimento (AC) oportunizou as atividades para que os licenciandos utilizassem os conceitos desenvolvidos na OC para analisarem e interpretarem as situações propostas na problematização inicial (Quadro 1).

$\mathrm{Na}$ AC, aplicou-se um Jogo Didático denominado “Twister Químico Radioatividade" ${ }^{1 "}$, cuja finalidade foi desenvolver e estimular o raciocínio lógico (via perguntas e respostas) dos participantes, além da concentração, da percepção de espaço e da coordenação motora. Finalizado esta aplicação, utilizou-se como procedimento de avaliação a aplicação de um questionário final, com o suporte de buscar indícios que respondessem à questão de pesquisa: "Quais foram as contribuições que a Situação de Estudo proporcionou para a sua formação inicial docente? Comente”.

O método escolhido para tratar os dados coletados nas respostas dos licenciandos foi a análise de conteúdo de Bardin (2011), uma vez que ela permite organizar e analisar os dados em três etapas: 1) a préanálise; 2) a exploração do material, e o 3 ) tratamento dos resultados, a inferência e a interpretação. Para isso, nas respostas coletadas na aplicação do questionário, optou-se por fazer a análise categorial, pois ela "pretende tomar em consideração a totalidade de um "texto", passando-o pelo crivo da classificação e do recenseamento, segundo a frequência de presença (ou de ausência) de itens de sentido" (BARDIN, 2011, p. 43).

\footnotetext{
${ }^{1}$ Jogo Twister químico pode ser adaptado de acordo com o conteúdo. Para esta atividade, formulamos questões de acordo com o conteúdo desenvolvido sobre Radioatividade, voltadas para responder a Problematização Inicial. O jogo é de autoria de Celita Trevizoli Poli, citado por Zapateiro (2017).
} 
Diante do método da categoria definida a priori: "Situação de Estudo do conteúdo de Radioatividade na formação inicial docente" (Quadro 4), buscou-se na exploração das respostas obtidas ("corpus" constituído) encontrar expressões ou palavras significativas no conteúdo das falas e, em seguida, organizar as subcategorias emergidas. Assim, utilizou-se como critério de recorte a codificação e a organização o “[...] léxico (classificação das palavras segundo o seu sentido, com emparelhamento dos sinônimos e dos sentidos próximos) [...]" (BARDIN, 2011, p. 147). Após várias releituras exploratórias das respostas obtidas nos questionários, pôde-se realizar o agrupamento das partes similares em um processo de codificação, separação das unidades de análise, enumeração e subcategorização (BARDIN, 2011). A seguir, os resultados obtidos na pesquisa.

\section{Resultados E Discussões}

No Quadro 4, é apresentada a análise dos resultados obtidos por mediação dos instrumentos utilizados durante a coleta de dados, que emergiram as 3 (três) categorias das unidades de análise, conforme o foco de observação.

Quadro 4 - Contribuições da Situação de Estudo para a formação inicial docente

\begin{tabular}{|c|c|c|}
\hline Categoria & Subcategorias & $\begin{array}{c}\text { Unidades de } \\
\text { análise }\end{array}$ \\
\hline \multirow{2}{*}{$\begin{array}{c}\text { Situação de Estudo do conteúdo } \\
\text { de Radioatividade na formação } \\
\text { inicial docente }\end{array}$} & $\begin{array}{c}\text { Aprendizagem e ensino na futura } \\
\text { profissão docente }\end{array}$ & 09 \\
\cline { 2 - 3 } & Abordar a história da Radioatividade & 04 \\
\cline { 2 - 3 } & $\begin{array}{c}\text { Ausência da Radioatividade no Ensino } \\
\text { Médio e na Graduação }\end{array}$ & 04 \\
\hline
\end{tabular}

\subsection{SUbCATEgoria: APRENDIZAGEM E ENSINO NA FUTURA PROFISSÃO DOCENTE}

Conforme o quadro 4, pode-se constatar que a SE colaborou com a formação inicial dos participantes, pois oportunizou para a maioria (09) aprender o conteúdo de radioatividade e como ensiná-lo em sua futura profissão docente, como comprovado em algumas respostas:

LM1: A outra contribuição foi na área de ensino, pois a situação desenvolvida apresentou estratégias de ensino (como vídeos, por exemplo) que podem ter boa aplicação na atuação como professor.

LF3: O assunto da radioatividade está diretamente ligado à qualidade de vida do cidadão (como podemos ver no acidente de Goiânia, que a ignorância sobre o conteúdo causou um acidente com aproximadamente 10 mil toneladas do lixo radioativo e contaminou uma área muito grande) eu, como futura professora, vou buscar trabalhar esse conteúdo nas minhas aulas.

LF5: Maior aproximação e aprofundamento com o conteúdo, o que é um ponto positivo [...]. 
LF7: Contribuiu no sentido de abordar o tema de uma forma clara e didática de um assunto que é amplo, de certa forma, com imagens. A maneira que organizou a apresentação é algo que facilita a compreensão [...]. Além de ter ensinado o conteúdo, como futuros professores, também aprendemos uma didática.

Diante das falas, percebe-se a importância de ofertar Situações de Estudos que colaborem com o processo formativo do licenciando para que percebam como relacionar a teoria e a prática ao trabalhar o conteúdo de radioatividade fundamentado na história da ciência. Nas respostas de LM1, LF3 e LF7, pode-se constatar o alcance de um resultado apontado por Martins (2007, p. 127, grifo nosso): "Do ponto de vista da formação de professores, não basta que tenhamos disciplinas de HFC nas licenciaturas. É preciso refletir sobre o como fazer". Portanto, para esses participantes, a SE aplicada os capacitou em como fazer, desenvolver, ensinar o conteúdo de radioatividade a partir do contexto histórico-social. Estes resultados corroboram com o que citam Maldaner e Zanon (2001), a SE precisa ser elaborada de acordo com a realidade de vida do indivíduo, ou seja, ter a relação do conteúdo químico com o cotidiano do licenciando, contribuindo para a sua formação cidadã.

$\mathrm{Na}$ resposta de LF3, fica evidente que obter este conhecimento científico pode evitar acidentes, como o ocorrido em setembro de 1987: “Acidente de Goiânia - Césio-137”, no qual catadores de papéis encontraram um equipamento hospitalar abandonado, e várias pessoas o manusearam, sem saber que dentro continha uma cápsula com material radioativo: Césio-137, Cloreto de Césio-137 ( $\mathrm{CsCl})$, sal parecido com o de cozinha $(\mathrm{NaCl})$, muito solúvel em água, facilmente absorvido pelo organismo (FELTRE, 2004).

\subsection{SubCategoria: Abordar a hiSTória da RADIOATIVIDAdE}

Esta subcategoria surgiu a partir das respostas de quatro licenciandos (Quadro 4), corroborando com o que pensam Martins (2006), Oki e Moradilho (2008): a inserção da história da ciência é um ponto primordial para uma aprendizagem efetiva, e contribui para formação do indivíduo, porque traz os contextos históricos, sociais, políticos e econômicos que emergiram do conhecimento científico como conhecemos hoje, e oportuniza obter uma visão mais ampla do desenvolvimento da ciência. Este saber foi constatado nas respostas:

LF2: Não conhecia a abordagem histórica, agora vejo o quanto é importante para o ensino. Mostrar aos alunos a história faz com que eles entendam que a ciência não é algo pronto e acabado.

LF7: A maneira que organizou a apresentação é algo que facilita a compreensão, começando a abordar a história da radioatividade.

LF10: A Situação de Estudo, além de acrescentar conhecimento sobre conceitos químicos, foi sensacional para entender a história desta descoberta química, que ao ser passada aos alunos de ensino médio provoca grande interesse. 
LM11: Contribuiu para que eu possa relacionar não só a radioatividade, mas também diversos conteúdos aos fatos históricos.

Estes resultados condizem com o que preconizam os Parâmetros curriculares Nacionais para o Ensino Médio (PCNEM) e a Base Nacional Comum Curricular (BNCC): a inserção da história da química durante os processos de ensino e de aprendizagem permite ao aluno entender a ciência como uma construção humana, ou seja, o processo de construção do conhecimento científico advém de reflexões e ideias conceituais científicas a fim de favorecer a qualidade de vida da sociedade (BRASIL, 2000; 2017). A radioatividade também deve ser abordada relacionando-a com fenômenos e avanços da tecnologia, principalmente no avanço da medicina, o que agrega ao ensino e à aprendizagem uma situação mais agradável e compreensível para o aluno (MEDEIROS; LOBATO, 2010).

Na literatura científica, pesquisas como de Martorano e Marcondes (2012) relatam sobre as dificuldades que professores de Química do Ensino Médio têm em abordar a História da Química, por exemplo, a falta de material e a carência de conhecimentos de como inserir a abordagem histórica para que possam usufruir em suas aulas. No entanto, os professores não têm uma formação apta para trabalhar com essa abordagem. Por isso, há a necessidade de pesquisas que elaborem materiais didáticos e ofertem cursos com propostas de como trabalhar a História da Química ainda na formação inicial, e em cursos para formação continuada.

\subsection{Subcategoria: Ausência da Radiontividade no Ensino Médio e na GRADUAÇÃo}

Conforme os dados do quadro 4, observa-se que três dos participantes citaram não ter sido abordado o conteúdo de radioatividade no Ensino Médio ou na Graduação. Para LM12, são assuntos pouco abordados na química, e no seu Ensino Médio: "LM12: [...] conteúdos poucos abordados no ensino de química [...]. A radioatividade foi um conteúdo que nunca foi abordado enquanto cursei o Ensino Médio [...]". Diante da fala de LM12, percebe-se que a SE colaborou para ele saber da existência do conteúdo de radioatividade. Este resultado corrobora com o que salienta Chassot (2016), o ensino de química representa ao cidadão um instrumento de leitura do mundo, porque possibilita que ele intérprete e intervenha nas questões cotidianas que envolvam processos químicos artificiais ou naturais.

Santos e Schnetzler (2010) também citam um dos objetivos do ensino de química quanto à formação cidadã, permitir que o aluno entenda e compreenda as informações fundamentais para participar na tomada de decisões junto à sociedade. Assim, a alfabetização científica sobre o conteúdo de radioatividade habilita o indivíduo a saber que o símbolo trifólio (desenho que 
representa o símbolo internacional da radiação) diz respeito a um material radioativo, portanto, deve ser manipulado por um responsável e com equipamento de proteção adequado, ou caso o mesmo esteja abandonado, deve-se acionar a Comissão Nacional de Energia Nuclear (CNEN).

Outros dois participantes também citaram não ter sido abordado o conteúdo de radioatividade na Graduação. Para LM1, o tema muitas vezes não é ensinado no Ensino Médio, e nem no Superior:

LM1: Uma das principais contribuições foi o fato de o tema abordado ser um tema que muitas vezes não é ensinado no Ensino Médio ou mesmo na Graduação [...].

LF5: Maior aproximação e aprofundamento com o conteúdo, o que é um ponto positivo, visto que é algo que não vemos no período da Graduação.

Estes resultados indicam que a Situação de Estudo permitiu aos licenciandos aprender o conteúdo de radioatividade, pois ainda não haviam sido abordados no Ensino Superior, como confirmado nas respostas de LM1 e LF5.

Com base nos resultados, entende-se que os licenciandos estudaram e aprofundaram os conhecimentos relacionados ao conteúdo de Radioatividade durante a aplicação da SE. Assim, confirma-se a necessidade de viabilizar ações educativas desse tema com os alunos no Ensino Médio, pois são saberes que integram os conteúdos estruturantes - Biogeoquímicos preconizados nas Diretrizes Curriculares da Educação Básica de Química (DCEBQ) do Estado do Paraná (PARANÁ, 2008).

Além disso, o assunto é selecionado e cobrado em vestibulares e no Exame Nacional do Ensino Médio - ENEM, a partir de fatos históricos que contribuíram para o progresso da ciência e tão presente no dia a dia das pessoas (tratamento do câncer, diagnóstico de doenças, conservação de alimentos, por exemplo). Neste contexto, para que o conteúdo de radioatividade seja trabalhado no Ensino Médio, é preciso repensar a estrutura curricular do referido curso, no sentido de englobá-lo durante a formação do licenciando em química para que ele seja apto a desenvolvê-lo em seu futuro trabalho docente.

\section{CONSIDERAÇõES FinAIS}

Foi possível evidenciar que o desenvolvimento da Situação de Estudo a respeito do conteúdo de radioatividade, a partir do seu contexto histórico-social, colaborou para a formação inicial docente dos licenciandos, proporcionando-lhes novos saberes, para que pudessem elaborar aulas que relacionem o saber cotidiano com o saber científico.

A análise das respostas permitiu verificar que os licenciandos consideraram que a abordagem de conteúdo a partir do contexto histórico-social durante a Situação de Estudo 
possibilita aos alunos a compreensão de que o desenvolvimento da ciência é permeado por vários fatores, descontruindo assim o conceito de ciência como algo pronto e acabado.

Diante dos resultados apresentados, entende-se que a elaboração e a aplicação da Situação de Estudo corroboraram com a proposta de Maldaner e Zanon (2001). Os autores evidenciam que a SE precisa ser elaborada de acordo com a realidade de vida do indivíduo e que tenha relação do conteúdo químico com o cotidiano do aluno, contribuindo assim para a sua formação cidadã.

Por isso, para estudos futuros, sugere-se a continuidade de aplicação da Situação de Estudo, pois os vários recursos didáticos utilizados (como o uso de imagens, vídeos, jogos, curiosidades, abordagem histórica e contextualizada), podem ser repensados/reestruturados/replanejados a partir do perfil da turma/alunos que o professor for trabalhar, tanto no Ensino Básico como na Graduação.

\section{REFERÊNCIAS}

BARDIN, Laurence. Análise de conteúdo. São Paulo: Edições 70, 2011.

BOGDAN, Robert; BIKLEN, Sari Knopp. Investigação qualitativa em educação. Tradução Maria João Alvarez, Sara Bahia dos Santos e Telmo Mourinho Baptista. Porto: Porto Editora, 1994.

BRASIL. Lei de Diretrizes e Bases da Educação Nacional. Lei número 9394, 20 de dezembro de 1996.

BRASIL. Ministério da Educação. Secretaria de Educação Média e Tecnológica. Parâmetros Curriculares Nacionais (Ensino Médio). Brasília: MEC, 2000.

BRASIL. Ministério da Educação. Diretrizes Curriculares Nacionais para os Cursos de Química. Parecer CNE/CES n ${ }^{\circ} 1.303$ de 06 de novembro de 2001. Brasília: Conselho Nacional da Educação, 2001.

BRASIL. Ministério da Educação. Orientações curriculares para o ensino médio: ciências da natureza, matemática e suas tecnologias, 2. Brasília: SEB, 2006.

BRASIL. Ministério da Educação. Secretaria de Educação Média e Tecnológica. Diretrizes Curriculares Nacionais para a formação inicial de professores. Brasília: MEC, 2015.

BRASIL. Ministério da Educação. Conselho Nacional de Educação. Conselho Pleno.

Resolução CNE/CP No 2, de 22 de dezembro de 2017. Brasília, DF: Conselho Nacional da Educação, 2017.

BRASIL. Ministério da Educação. Base Nacional Comum Curricular Educação. 2017 Disponível em: http://basenacionalcomum.mec.gov.br/images/BNCC_EI_EF_110518_versaofinal_site.pdf. Acesso em: 15 de ago. 2020. 
CARVAlHO, Anna Maria Pessoa de; GIL PÉREZ, Daniel. Formação de Professores de Ciências: Tendências e inovações. Editora Cortez, 10. ed., v. 28, São Paulo, 2011.

CHASSOT, Attico. Alfabetização científica: questões e desafios para a educação. 7.ed. Ijuí: Unijui, 2016.

CHAVES, Lígia M. Martinho Pereira; SANTOS, Wildson Luiz Pereira dos; CARNEIRO, Maria Helena da Silva. História da Ciência no Estudo de Modelos Atômicos em Livros Didáticos de Química e Concepções de Ciência. Química Nova na Escola, v. 36, n. 4, p. 269-279, 2014.

DATTEIN, Raquel Weyh; GULLICH, Roque Ismael da Costa; ZANON, Lenir Basso. Escritas reflexivas compartilhadas como estratégia de formação inicial: a pesquisa no ensino e na iniciação à docência em ciências. Ensino \& Pesquisa, v. 16, n. 1, 2018.

DELIZOICOV, Demétrio; ANGOTTI, José André; PERNAMBUCO, Marta Maria. Ensino de Ciências: fundamentos e métodos. 2. ed. São Paulo: Cortez, 2007.

DIAS, Néryla Vayne Alves; CARDOSO, Valdinei Cézar; DEBASTIANI NETO João. Algumas reflexões sobre o papel da participação em grupos de pesquisa para a formação de licenciandos em física. Arquivos do Museu Dinâmico Interdisciplinar. v. 19 n. 2-3, pp. 53 72. 2015.

FRISON, Marli Dallagnol et al. Conhecendo o câncer, um caminho para a vida: uma situação de estudo como possibilidade de mudança no fazer cotidiano escolar. In: GALIAZZI, M. do C. et al. (Org.). Construção curricular em rede na Educação em Ciências: uma Proposta de Pesquisa em Sala de Aula. 1. Ijuí: Unijuí, 2007, p. 337-355

GALIAZZI, Maria do Carmo. Educar pela pesquisa: ambiente de formação de professores de ciências. Ijuí: Unijuí, 2014.

KINALSKI, Alvira C. et al. Situação de Estudo: Proposta Transdisciplinar da Área das Ciências da Natureza e suas Tecnologias no Ensino Médio do Centro de Educação Básica de Francisco de Assis. In: MORAES, R. et. al. Construção Curricular em Rede na Educação em Ciências uma Proposta de Pesquisa em Sala de Aula. 1. Ijuí: Unijui, 2007, p. 357-373.

MALDANER, Otavio Aloisio. A Formação Inicial e Continuada de professores de Química. 3 ed. Ijuí: UNIJUÍ, 2006.

MALDANER, Otavio Aloisio. Desenvolvimento de currículo e formação de professores de ciência da natureza, matemática e suas tecnologias. In: FRISO, Marli Dallagnol. (org.). Programa de Melhoria e Expansão do Ensino Médio: curso de capacitação de professores da área de Ciências da Natureza, Matemática e suas Tecnologias. $1^{\mathrm{a}}$ ed. Ijuí: Editora UNIJUÍ, p. 7-17, 2007.

MALDANER, Otavio Aloisio; ZANON, Lenir Basso. Situação de Estudo: uma organização do ensino que extrapola a formação disciplinar em Ciências. In: MORAIS, R.; MARCUSO, R. (Orgs.). Educação em Ciências: produção de currículos e formação de professores. Ijuí: UNIJUÍ-RS, p. 43-64, 2004. 
MARTINS, Roberto de Andrade. Introdução. A história das ciências e seus usos na educação. In: SILVA, C. C. (ed.). Estudos de história e filosofia das ciências: subsídios para aplicação no ensino. São Paulo: Livraria da Física, 2006.

MARTINS, André Ferrer Pinto. História e Filosofia da Ciência no ensino: há muitas pedras nesse caminho, Caderno Brasileiro de Ensino Física, v. 24, n. 1: p. 112-131, abril 2007.

MARTORANO, Simone Alves de Assis; MARCONDES, Maria Eunice

Ribeiro. Investigando as ideias e dificuldades dos professores de química do ensino médio na abordagem da história da química. História da Ciência e Ensino: construindo interfaces, v. 6, 2012, p. 16-31.

MATTHEWS, Michael R. História, Filosofia y Enseñanza de las Ciencias: la aproximación actual, Enseñanza de las Ciencias, 12 (2), 255-277, 1994.

MATTHEWS, Michael R. Science teaching: the role of history and philosophy of science. New York: Routledge, 1994.

MEDEIROS, Miguel de Araújo; LOBATO, Anderson César. Contextualizando a Abordagem de Radiações no Ensino de Química. Ensaio - Pesquisa em Educação em Ciências, vol. 12, n. 3, p. 65-83, 2010.

MIZUKAMI, Maria da Graça Nicoletti. Ensino: As abordagens do Processo. São Paulo: EPU, 1986.

MUENCHEN, Cristiane; DELIZOICOV, Demétrio. Os três momentos pedagógicos e o contexto de produção do livro "Física". Ciênc. Educ., Bauru, v. 20, n. 3, p. 617-638, 2014.

NEVES, Marcos Cesar Danhoni. A história da ciência no ensino de física. Revista Ciência \& Educação, 1998, 5 (1), pp. 73-81.

OKI, Maria da Conceição Marinho; MORADILHO, Edílson Fortuna de. O ensino de História da Química: contribuindo para a compreensão da natureza da ciência. Ciência e Educação, Bauru, vol.14, n.1, pp. 67-88, 2008.

PARANÁ. Secretaria de Estado da Educação. Diretrizes Curriculares Da Educação Básica Química. Paraná, 2008. 76 p.

SANTOS, Wildson Luiz Pereira dos; SCHNETZLER, Roseli Pacheco. Educação em Química: compromisso com a cidadania. Ijuí: Unijuí, 2010.

SANTOS, Wildson Luiz Pereira dos; MALDANER, Otavio Aloisio. Ensino de Química em Foco. Ijuí: Unijuí, 2010.

SAVIANI, Demerval. Escola e Democracia. São Paulo: Cortez Editora, 25 a edição, 1991.

SAVIANI, Dermeval. Formação de professores: aspectos históricos e teóricos do problema no contexto brasileiro. Revista Brasileira Educação, vol.14, n.40, pp.143-155, 2009. 
SOUZA, Aiala Silva; CHAPANI, Daisi Teresinha. Formação universitária de professores: a participação de licenciandos de ciências biológicas em grupos de pesquisa. Revista de Ensino de Ciências e Matemática, v. 10, n.3, p. 111-131, 2019.

SCHÖN, Donald. Formar professores como profissionais reflexivos. In: NÒVOA, A. (org.). Os professores e sua formação. 2 ed. Lisboa: Dom Quixote, 1995.

TEIXEIRA, Paulo Marcelo Marini. Iniciação à pesquisa: um eixo de articulação no processo formativo de professores de Ciências Biológicas. Ens. Pesqui. Educ. Ciênc, v. 5, n. 1, pp.5$18,2003$.

ZANON, Lenir Basso; MALDANER, Otavio Aloisio. A Química na Inter-Relação com outros campos do saber. In. SANTOS, Wildson Luiz Pereira dos; MALDANER, Otavio Aloisio. (Orgs.) Ensino de Química em Foco. Ijuí: Unijuí, 2010. p. 102-130.

ZAPATEIRO, Gean Aparecido. Formação inicial de licenciandos em Química: uma proposta de situação de estudo para abordar o conteúdo básico de radioatividade. 2017. Trabalho de Conclusão de Curso (Graduação em Licenciatura em Química) - Departamento de Química, Universidade Tecnológica Federal do Paraná-UTFPR. Londrina, Paraná, 2017.

Recebido em: 15 de agosto de 2020.

Aprovado em: 20 de outubro 2020. 